\title{
ASTHMA AND ALLERGIC RHINITIS AMONGST CHILDREN HAVING CELIAC DISEASE.
}

1. FCPS (Pediatrics Medicine) Assistant Professor

Department of Pediatrics Unit-II Children Hospital Chandka Medical College/SMBBMU, Larkana.

2. MBBS

Postgraduate Resident

Department of Pediatric Medicine

The Children's Hospital and

The Institute of Child Health, Multan

3. FCPS (Pediatrics Medicine) Assistant Professor

Department of Pediatrics Medicine Ghurki Trust Teaching Hospital, Lahore.

4. FCPS (Pediatrics Medicine) Senior Registrar

Rai Medical College/

Doctor's Trust Teaching Hospital, Sargodha.

5. FCPS (Pediatrics Medicine) Fellow in Pediatrics Neurology Agha Khan Hospital, Karachi.

Correspondence Address:

Dr. Fazal Ur Rehman

Department of Pediatric Medicine

The Children's Hospital and

The Institute of Child Health, Multan.

fazal171@gmail.com

Article received on:

01/02/2019

Accepted for publication:

$22 / 05 / 2019$
Asif Ali Khuhro', Fazal ur Rehman ${ }^{2}$, Waqas $\mathrm{Ali}^{3}$, Najmi Usman ${ }^{4}$, Sanam Bano Rajper ${ }^{5}$

ABSTRACT... Objectives: Relationship amongst celiac disease (CD) and lung diseases has been discussed in the past. Studies have documented that CD is linked with lung diseases. $\mathrm{CD}$ has also been described to complement asthma. This study was planned to document the prevalence of asthma as well as allergic rhinitis in confirmed cases of $C D$ and conducted pulmonary function testing in children aged 5 to 16 years while comparing them with controls. Study Design: Cross sectional study. Setting: Department of Pediatrics Medicine, Children Hospital Chandka Medical College / Shaheed Mohtarma Benazir Bhutto Medical University, Larkana. Period: From $1^{\text {st }}$ January 2018 to $30^{\text {th }}$ June 2018. Material \& Methods: We enrolled 50 confirmed cases of $C D$ along with 100 controls with non specific abdominal pain. All were aged 6 to 16 years, of both genders. Demographics as well as questions related to asthma and allergic rhinitis were noted. Results: Amongst a total of 150 children, 61 (40.7\%) male and 89 (59.3\%) female. Overall mean age amongst children was 9.80 years with standard deviation of 2.6 years. A total of $40(26.7 \%)$ children who had weight below the $3^{\text {rd }}$ percentile while $36(24.0 \%)$ had height below the 3rd percentile. Most children, 82 (54.7\%) had normal BMI. Weight below the $3^{\text {rd }}$ percentile and height below the $3^{\text {rd }}$ percentile were of statistical significance as children with a weight and height below the 3rd percentile were significantly higher in the CD group ( $P=$ 0.026 and $P=0.005$, respectively). Asthma and allergic rhinitis characteristics were not much different between the two groups $(p>0.05)$. The Pulmonary function test (PFT) results showed that $7(14.0 \%)$ cases with CD and $12(12.0 \%)$ controls had obstructive pulmonary changes $(p>0.05)$. Conclusion: Rates of Asthma and allergic rhinitis in children having CD were not significantly higher in comparison to controls. No linkage between asthma and allergic rhinitis symptoms was seen children having $C D$.

Key words: $\quad$ Asthma, Allergic Rhinitis, Celiac Disease, Pulmonary Function Test.

Article Citation: Khuhro AA, Fazal ur Rehman, Ali W, Usman N, Rajpar SB. Asthma and Allergic Rhinitis amongst children having Celiac disease. Professional Med J 2019; 26(12):2151-2155. DOI: 10.29309/TPMJ/2019.26.12.3498

\section{INTRODUCTION}

Celiac disease $(C D)$ was initially discussed in 1887 and is known to be a life-long autoimmune disease. $C D$ is described as damage to the mucosa of small intestinal subsequent to the ingestion of gluten-foods in those individuals who are genetically predisposed..$^{1-4}$ Globally, the prevalence of $C D$ is about $1 \%$ in general population whereas in Europe, it is noted to be from 1 to $3 \%$. In children its prevalence is around $0.5 \%$ to $1 \%$. It is estimated that amongst children, $90 \%$ of CD cases are undiagnosed which means that these children are unable to get any treatment. ${ }^{5-9}$

The pathogenesis of $C D$ is complex involving factors that are genetic, immunological as well as environmental. Clinical presentation of $C D$ is not restricted to only gastrointestinal (Gl) symptoms as it can exhibit in the form of non Gl symptoms as well. Patients without any symptoms but with serology as well as pathology related to small intestine which is correlated with $C D$ portrays that the prevalence is much higher that what is currently considered..$^{10-12}$

Asthma is frequently seen in children and is said to affect $10-20 \%$ of children around the globe. ${ }^{5,13,14}$ In Pakistan, its prevalence is around $20 \%$ in pediatric population. ${ }^{15,16}$ Allergic rhinitis is described as paroxysmal sneezing, nasal discharge as well as congestion and usually is adjunct to itching related to eyes and nose. ${ }^{17}$ 
Relationship amongst $\mathrm{CD}$ and lung diseases was $1^{\text {st }}$ described in the 1970 by Hood et al. ${ }^{18}$ Studies have documented that CD is linked with lung diseases. $C D$ has also been described to complement asthma. As CD is described as autoimmune disease, also linked with $T$ helper type 1 and type 2 cells, these are said to play the dominant role in pathophysiology of diseases like asthma as well other allergic disorders. ${ }^{19-22}$

While no work finding out the possible association of CD with asthma or any allergic disorder is done in Pakistan, few international studies are there but with inconsistent findings. Some suggested that allergic disorders may occur with autoimmune diseases as both have some common risk factors of genetic and environmental origin. We planned this study to document the prevalence of asthma as well as allergic rhinitis in confirmed cases of CD and conducted pulmonary function testing in children aged 5 to 16 years while comparing them with controls.

\section{MATERIAL AND METHODS}

This was a cross sectional study conducted at Department of Pediatrics Medicine, Children Hospital Chandka Medical College / Shaheed Mohtarma Benazir Bhutto Medical University, Larkana. We enrolled 50 confirmed cases of CD along with 100 controls with non specific abdominal pain. All these children were aged 6 to 16 years, of both genders. Demographics as well as questions related to asthma and allergic rhinitis were noted on a designed proforma.

CD was diagnosed on serological testing ( $\lg A$ and IgG endomysial antibodies (EMA), IgA and IgG gliadin antibodies, and IgA and IgG human tissue transglutaminase antibodies), small bowel biopsy performed during upper endoscopies, and histological evidence of villous atrophy with crypt hyperplasia as well as an increase in intraepithelial lymphocytes. ${ }^{23}$ Asthma was noted in children whose parents/guardians informed about history of wheezing at anytime while active asthma was documented with a response of wheezing in the last 1 year. PFT was done and spirometry measurements were noted in every child by a consultant pulmonologist. Best FEV1,
FVC as well FEV1/FVC were recorded. An FEV1 of less that $80 \%$ or FEV1/FVC ration of more than $80 \%$ were noted as obstructive changes. ${ }^{23}$ In confirmed cases of CD, adherence to diet was labeled when cases were noted to have answered with gluten-free diet and were found to be negative for EMA-antibody.

SPSS version 20 was used for data entry and statistical analysis. Descriptive statistics were calculated for the study variables chi square test was applied to compare the data between the two study groups while $P$ value less than 0.05 was taken as of statistical significance.

\section{RESULTS}

Amongst a total of 150 children (50 cases with $\mathrm{CD}$ and 100 controls with non-specific abdominal pain), there were 61 (40.7\%) male and 89 (59.3\%) female. Overall mean age amongst children was 9.80 years with standard deviation of 2.6 years. A total of $40(26.7 \%)$ children who had weight below the $3^{\text {rd }}$ percentile while $36(24.0 \%)$ had height below the 3rd percentile. Most children, 82 $(54.7 \%)$ had normal BMI. There were 24 (16.0\%) children who had positive parental history of asthma and 28 (18.7\%) with positive parental history of allergic rhinitis. In the CD groups, 41 (82\%) children were having full adherence to gluten-free diet.

When both groups were compared for demographic features, no statistical difference was found in terms of gender, age, BMI or parental history of asthma or allergic rhinitis ( $p$ $>0.05)$ but for weight below the $3^{\text {rd }}$ percentile and height below the $3^{\text {rd }}$ percentile, the difference was of statistical significance as children with a weight and height below the 3rd percentile were significantly higher in the $C D$ group $(P=0.026$ and $P=0.005$, respectively).

Asthma and allergic rhinitis characteristics when compared amongst both groups were of not much different as no statistical significance was found between the two groups ( $p>0.05)$.

The PFT results amongst the both groups showed that $7(14.0 \%)$ cases with CD and 12 (12.0\%) 
controls had obstructive pulmonary changes but the difference amongst the both groups were of

no significance $(p>0.05)$.

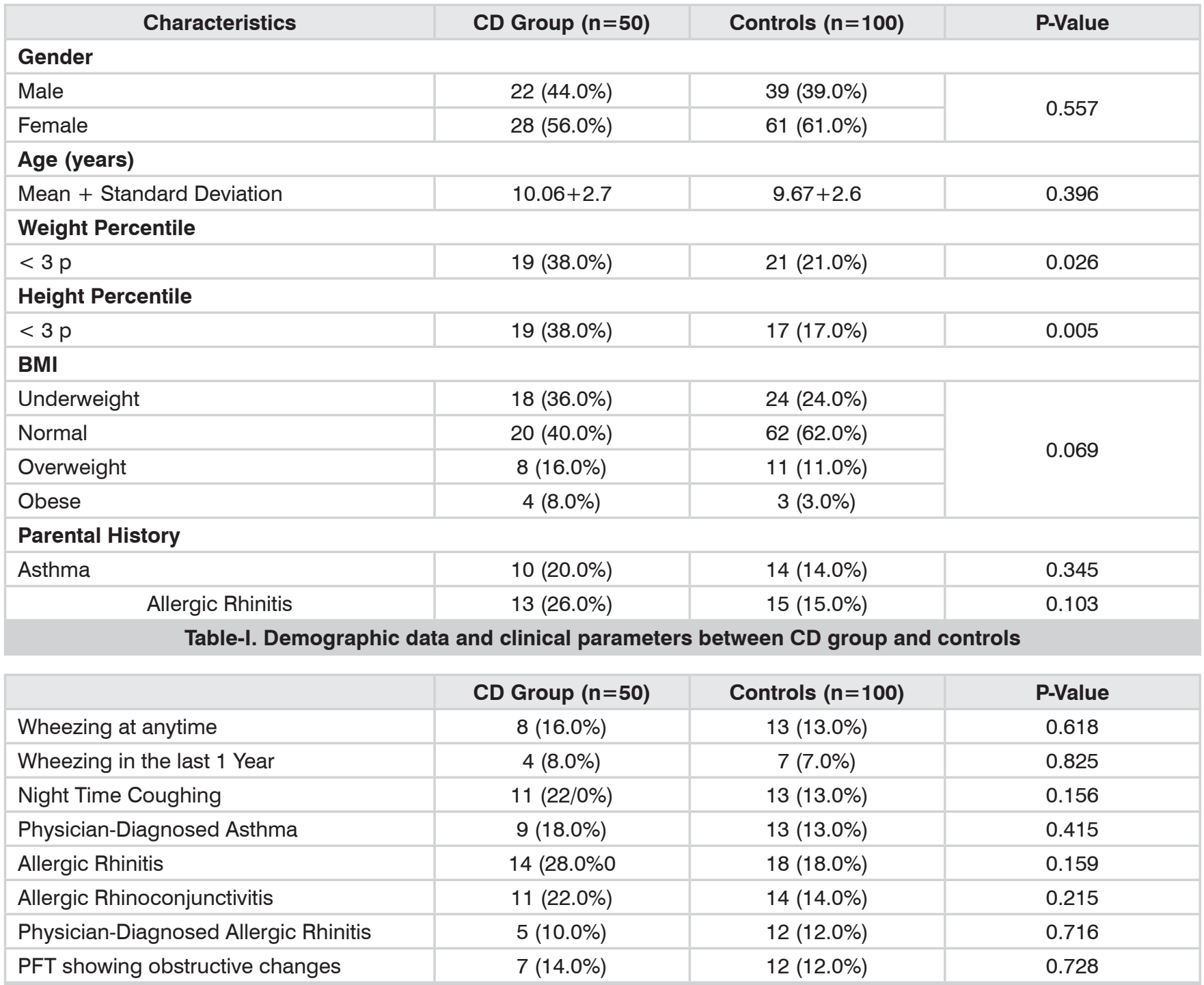

Table-II. Asthma, allergic rhinitis and PFT in CD group and controls

\section{DISCUSSION}

More attention is being given to the linkage between allergic and autoimmune disorders in the recent years. Research evaluating this unique relationship has found that these two distinct disease groups are often seen in conjunction. Although the exact causes of concomitance are unknown but their common prevalence have surely been discussed in the recent years. ${ }^{19-22}$

A study from Switzerland ${ }^{21}$ having large number of cases with CD as well controls found an increased hazard ratio of asthma as 1.61 (95\%
$\mathrm{Cl}$ : 1.50-1.72) for cases with CD. Incidence of hospitalization was significantly raised in cases having $\mathrm{CD}$ and asthma. Common genetic as well as environmental factors have been argued to be the causes of CD along with asthma. Kero and colleagues ${ }^{22}$ showed that the risk of asthma was 7.26 times increased in cases who had been diagnosed with CD. Zauli and coworkers ${ }^{24}$ found a positive association of CD with atopy and noted that an overall prevalence of $1 \%$ amongst atopic cases in Italy. The same study also summarized that atopic cases should always be further analyzed for a possibility of CD. In another study, 
asthma was found to be present in $28 \%$ of cases with CD while $11 \%$ in the general population. ${ }^{19}$

In our study, most of the children had normal BMl while there was no statistical difference between the two groups. A study done by Venkatasubramani $\mathrm{N}$ et al in $2010^{25}$ found different results where they noted significant number of obese children having positive associations with CD.

In comparison to previous studies, ${ }^{17,23,24}$ we found somewhat higher rates of physician diagnosed asthma and allergic rhinitis in the present study. We found more cases of CD having asthma and allergic rhinitis features but the difference comparing asthma as well as allergic rhinitis and their characteristics were not statistically different between cases and controls. As compared to previous findings, ${ }^{21,23}$ we found similar rates of asthma and allergic rhinitis symptoms in the present study.

To the best of our knowledge, only one previous study exist ${ }^{23}$ enquiring asthma and CD relationship while also looking into PFTs while this was the $1^{\text {st }}$ study of such profile in Pakistan. This study can further add to the baseline figures that exist regarding possible relationship of allergic disease in children having CD and surely will provide interesting insights if compared with the future studies. Although we did not have a huge sample size but $C D$ as a disease has seen very few studies conducted in our area especially in pediatric population. Lack of follow up and data are also limitations of this study.

\section{CONCLUSION}

Rates of Asthma and allergic rhinitis in children having $C D$ were not significantly higher in comparison to controls. No linkage between asthma and allergic rhinitis symptoms was seen children having CD. Further studies with big samples having follow-up are needed to evaluated any possible linkage between these diseases. Copyright@ 22 May, 2019.

\section{REFERENCES}

1. Husby S, Koletzko S, Korponay-Szábó IR, Mearin ML, Phillips A, et al. ESPGHAN guidelines for the diagnosis of coeliac disease in children and adolescents. An evidence-based approach 2012; 54:136-60.

2. Abadie V, Sollid LM, Barreiro LB, Jabi B. Integration of genetic and immunological insights into a model of celiac disease pathogenesis. Annu Rev Immunol 2011; 29:493-525.

3. Green PHR, Jabri B. Coeliac Disease. Lancet 2003; 362:383-391.

4. Kaukinen K, Partanen J, Maki M, Collin P (2002) HLA$\mathrm{DQ}$ typing in the diagnosis of celiac disease. Am J Gastroenterol 97: 695-699.

5. Mantegazza C, Zuccotti G, Dilillo D, Koglmeier J. Celiac disease in children: A Review. Int J Dig Dis. 2015; 1(19):1-7.

6. Csizmadia CG, Mearin ML, von Blomberg BM, Brand $\mathrm{R}$, Verloove-Vanhorick SP. An iceberg of childhood coeliac disease in the Netherlands. Lancet 1999; 353:813-4.

7. Carlsson AK, Axelsson IE, Borulf SK, Bredberg AC, Ivarsson SA. Serological screening for celiac disease in healthy 2.5-year-old children in Sweden. Pediatrics 2001; 107: 42-45.

8. Maki M, Mustalahti K, Kokkonen J, Kulmala P, Haapalahti $\mathrm{M}$, et al. Prevalence of Celiac disease among children in Finland. N Engl J Med 2003; 348: 2517-24.

9. Catassi C, Rätsch IM, Fabiani E, Rossini M, Bordicchia $\mathrm{F}$, et al. Coeliac disease in the year 2000: exploring the iceberg. Lancet 1994; 343:200-3.

10. Murch S, Jenkins $H$, Auth $M$, Bremner R, Butt $A$, et al. Joint BSPGHAN and Coeliac UK guidelines for the diagnosis and management of coeliac disease in children. Arch Dis Child 2013; 98: 806-11.

11. Schuppan D, Junker Y, Barisani D. Celiac disease: From pathogenesis to novel therapies. Gastroenterology 2009; 137: 1912-33.

12. Van B H GP, Mulder CJ. Pioneer in the gluten free diet: Willem-Karel Dicke1905-1962, over 50 years of gluten free diet. Gut 1993; 34:1473-5.

13. Anandan C, Nurmatov U, van Schayck OC, Sheikh A. Is the prevalence of asthma declining? Systematic review of epidemiological studies. Allergy. 2010; 65(2):152-67. 
14. Ones U, Akcay A, Tamay Z, Guler N, Zencir M. Rising trend of asthma prevalence among Turkish schoolchildren (ISAAC phases I and III). Allergy. 2006; 61(12):1448-53.

15. Waqar MA, Khan M, Hasnain SM, Saleem A, Shaukat $S$, et al. Prevalence of allergy and asthma in school children of Islamabad, Pakistan. World Applied Sciences Journal 2009; 6(3):426-32.

16. Settipane RA. Demographics and epidemiology of allergic and nonallergic rhinitis. Allergy Asthma Proc. 2001; 22(4):185-9.

17. Hood J, Mason AM. Diffuse pulmonary disease with transfer defect occurring with coeliac disease. Lancet. 1970; 1(7644):445-7.

18. Ellul P, Vassallo M, Montefort S. Association of asthma and allergic rhinitis with celiac disease. Indian $\mathrm{J}$ Gastroenterol. 2005; 24(6):270-1.

19. Ludvigsson JF, Hemminki K, Wahlstrom J, Almqvist C. Celiac disease confers a 1.6-fold increased risk of asthma: A nationwide populationbased cohort study. J Allergy Clin Immunol. 2011; 127(4):1071-3.
20. Hemminki K, Li $X$, Sundquist J, Sundquist $K$. Subsequent autoimmune or related disease in asthma patients: Clustering of diseases or medical care?. Ann Epidemiol. 2010; 20(3):217-22.

21. Kero J, Gissler M, Hemminki E, Isolauri E. Could TH1 and TH2 diseases coexist? Evaluation of asthma incidence in children with celiac disease, type 1 diabetes, or rheumatoid arthritis: a register study. J Allergy Clin Immunol. 2001; 108(5):781-3.

22. Ozdogan S, Urganci N, Usta M, Kizilkan NU. Prevalence of asthma and allergic rhinitis in children with celiac disease. Iran J Pediatr. 2016 December; 26(6):e6358.

23. Zauli D, Grassi A, Granito A, Foderaro S, De Franceschi L, Ballardini $G$, et al. Prevalence of silent coeliac disease in atopics. Dig Liver Dis. 2000; 32(9):775-9.

24 Venkatasubramani N, Telega G, Werlin SL. Obesity in pediatric celiac disease. J Pediatr Gastroenterol Nutr. 2010; $51(3): 295-7$.

\begin{tabular}{|c|c|c|c|}
\hline \multicolumn{4}{|c|}{ AUTHORSHIP AND CONTRIBUTION DECLARATION } \\
\hline Sr. \# & Author(s) Full Name & Contribution to the paper & Author(s) Signature \\
\hline 1 & Asif Ali Khuhro & $\begin{array}{l}\text { Methodology, Data Collection, } \\
\text { Proof reading. }\end{array}$ & \\
\hline 2 & Fazal ur Rehman & $\begin{array}{l}\text { Methodology, Literature Review, } \\
\text { Data analysis, Drafting. }\end{array}$ & sim \\
\hline 3 & Waqas Ali & $\begin{array}{l}\text { Methodology, Literature review, } \\
\text { Discussion. }\end{array}$ & $\cos 2$ \\
\hline 4 & Najmi Usman & $\begin{array}{l}\text { Methodology, Literature review, } \\
\text { Discussion. }\end{array}$ & \\
\hline 5 & Sanam Bano Rajper & $\begin{array}{l}\text { Methodology, Literature review, } \\
\text { Discussion. }\end{array}$ & thetion \\
\hline
\end{tabular}

